\title{
Space Security and Cybersecurity in Poland
}

\author{
Małgorzata Polkowska
}

\begin{abstract}
This article refers to the definitions of: "space security" and "cybersecurity". Both terms are strictly connected to the national defense and can be part of international law and national law of security. It seems that those two aspects of security are well regulated in Europe and Poland. Making such a regulation on international level is still a challenge. Poland is more active in space and legislation since the Polish Space Agency was created. The Security in Space began the very important factor for the national defense. Polish entrepreneurs involved in space business should be aware of this while undertaking space activities. Space has reached an easy access and became the target for intruders. That is why the regulators of cybersecurity and space security should be aware of this new threat and cooperate together in case to make the law practicable and effective.
\end{abstract}

\section{Introduction}

In such a broad term as "security", both: "space security" and "cybersecurity" aspects can be found. Both terms are strictly connected to the national defense and can be part of international law and national law of security. It seems that those two aspects of security are well regulated in Europe and Poland. Making such a regulation on international level is still a challenge. While talking about cybersecurity (which seems more Earth oriented issue) we cannot forget about space security (connected to Outer Space) and all regulations connected.

\footnotetext{
M. Polkowska ( $ه)$

Instytut Prawa/Institute of Law, Akademia Sztuki Wojennej w Warszawie/War Studies

University in Warsaw, Warsaw, Poland

e-mail: m.polkowska@akademia.mil.pl

(C) The Author(s) 2022 


\section{Polish Space History and Polish Space Business}

The history of Space in Poland is much longer than expected. The beginnings of Polish astronomical activity date back to the fifteenth Century and the Copernican revolution. The most famous figure of this period was Nicolaus Copernicus, whose work "On the rotation of celestial spheres" presented in detail the heliocentric vision of the planetary system. In the sixteenth and seventeenth centuries, Jan Hevelius (mathematician, astronomer) and Kazimierz Siemienowicz (engineer, rocket constructor) contributed to the development of Polish cosmic thought. In the twentieth Century, Polish scientists were involved in cooperation with the USSR, among others, in the Interkosmos programme. The first Polish device for measuring solar radiation was sent into orbit on board of the Copernicus satellite-500 (in 1973). Other achievements include the experiment of crystallization in microgravity conditions. Three years later the Space Research Centre of the Polish Academy of Sciences (CBK) was established for space exploration and development of space technologies. In the 1970s, the practical use of satellite images and satellite communications in Poland also began. The 1970s also saw participation in several space missions (by 1999, a total of 60 Polish devices for performing experiments in physics had been deployed). In 1978, the Polish astronaut Mirosław Hermaszewski travelled in Space on board the Soviet ship Soyuz-30. The purpose of the journey was an 8-day mission to carry out experiments at the Soviet station Salut-6.

The research of Polish scientists included mainly astrophysics (solar system), the study of planets and small celestial bodies of the solar system, the study of the sun, the study of phenomena occurring in space plasma in interplanetary and periplanetary space, Earth exploration by satellite geodesy and satellite remote sensing (checking the degree of pollution of ponds, forests, soil moisture, weather forecasts), the discovery of planets outside the sun, cooperation in the construction of a telescope in South Africa.

After 1989, political changes made it possible to develop cooperation with countries outside the Eastern bloc. In 1994, Poland signed an agreement with ESA on cooperation in the peaceful use of space, which was extended in 2002. On its basis, Poles could participate in ESA's scientific programmes, which resulted in the presence of Polish devices on most of ESA's flagship research missions (CassiniHuygens, Integrat, Mars Express, Rosetta, Venus Express and Herschel). The beginning of the twenty-first Century and Polish accession to the EU brought an intensification of cooperation with ESA. In 2007, an agreement on a European Collaborating State (PECS) was signed with ESA, and thanks to the creation of this mechanism, 45 projects were financed by Polish companies, research institutions and universities in cooperation with $\mathrm{ESA}^{1}$ Space activities like few other areas of economic activity require extremely intensive international cooperation. For Poland, the main direction of such cooperation is Europe, where, apart from

\footnotetext{
${ }^{1}$ Polkowska and Ryzenko (2016), p. 339.
} 
individual countries, space activities are conducted by the European Union (EU) and a dedicated organization-ESA.

In the 2007-2013 financial perspective, the EU allocated about EUR 4.9 billion for space projects, i.e. EUR 700 million annually. Poland, with its share of about $3.2 \%$ in the general EU budget, proportionally co-financed EU space programmes with the amount of about 22.4 million Euro annually. In the current financial perspective 2014-2020, the EU plans to spend a total of approximately EUR 11.8 billion on space activities (nearly 2.5 times more than in the previous one), of which the estimated share of Poland will amount to approximately EUR 378 million.

These figures show Poland's relatively large financial involvement in the financing of European space-related activities. However, until recently, there were no mechanisms to facilitate access to these funds for space activities in Poland. This was mainly due to the fact that EU space projects are implemented within the framework of industrial cooperation, which is shaped in the programmes of a separate organisation-ESA. As a result, the possibilities of actual participation in EU projects are extremely limited for countries that are not members of ESA.

In November 2012 Poland joined ESA, which opened the way for faster development of space technologies and satellite techniques through the possibility of full participation in most of the Agency's programmes. Poland has become the 20th member of ESA, paying a contribution of around $€ 30$ million per year. Poland's membership in ESA provides an opportunity to create and strengthen the relevant skills and potential of Polish industry, develop cooperation between the environment, access to joint programmes, ensure coherence between ESA and Poland.

At the same time, the possibility to engage in industrial cooperation in ESA programmes has opened the way to real participation in EU space projects. It is fully understandable that the opportunity to ensure a partial flow of Polish investment in the EU space programme back to Poland, in the form of investment in cutting-edge sectors of the economy, is of great importance for Polish economic policy.

Currently, the Polish space policy community, based on 6 years of experience of actual implementation of international cooperation with ESA, still formulates a similar answer to the question "why should Poland invest in space?"

In the context of these considerations, it is necessary to present the way in which expectations in relation to measurable benefits from Polish membership in ESA are determined. The following elements should be taken into account:

(1) geographical return-return to Poland of the majority of funds transferred to ESA;

(2) inflow of EU funds allocated to space programmes;

(3) growth in sales of Polish companies participating in ESA programmes;

(4) increase in the number of new jobs in the area of high technologies;

(5) increase in the level of innovativeness of the participating entities-secured intellectual property rights and the effects of their commercialisation

A large number of companies interested in participating in ESA programmes confirms that Poland has a significant potential of innovative enterprises, and at the same time these companies are interested in the development of new technologies- 
on condition that it is possible to obtain public support. It is still too early to assess the effectiveness of these mechanisms. The translation of such works into actual market sales of these companies will take place at the earliest after 3-4 years, and in the case of companies developing strictly space technologies even after several years.

Cooperation with ESA is aimed at increasing the competence of the Polish industry and consequently its greater involvement in the implementation of the European space programme. Poland's participation in ESA programmes gives wider access to technology, the possibility of transferring new technologies to industry, participation in expenditures on modern industries and opens up opportunities for scientific cooperation. It is extremely important that ESA has a geographical return, so contracts are allocated in proportion to the share of the Agency's funding.

\section{Polish Space Legislation}

Poland is more active in space and legislation since the Polish Space Agency was created (POLSA). This Agency is a governmental executive body, subject to the Prime Minister. It consists of civilian and military personnel. It was established by the Act of 26 September 2014 and became fully operational at the end of 2015 . $^{2}$ This act has been amended in 2018. The agency participates in fulfilling the strategic goals of the Republic of Poland by supporting the utilization of satellite systems and the development of space technologies. The main tasks of POLSA cover the following 5 areas: coordinating the activity of the Polish space sector on the national and international level, representing Poland in relations with international space sector organizations, supporting national science and business projects associated with space technologies, popularizing the use of satellite data by public administration and increasing the defensive capabilities of the country. The agency is executive in nature in accordance with the Act from 27 August 2009 in public financing (Article-Act of 26 September 2014) and it can create local branches of the agency. The headquarters of the Agency is located in Gdansk (Article 3. The activities of the Agency are under the auspice of the President of the Council of Ministers (Article 2). The duties of the agency are described in Article 3. The President of the POLSA Council is composed of representatives of the government- one from each administration and four representatives of scientists and the industry with recognized achievements in research or business and chosen based on their knowledge competence in areas concerning POLSA activities (Article 14). ${ }^{3}$

Polish Space law is still waiting for the Parliamentary approval. Several versions of the draft have been developed; at present, the Government Legislation Centre

\footnotetext{
${ }^{2}$ Act on Polish Space Agency, Polish Journal of Laws of 2014, item 1533.

${ }^{3}$ Polkowska (2016), pp. 68-69.
} 
website has published a draft law on space activities and the National Register of Space Objects. The Act regulates: the rules of performing space activities and the rules of maintaining the National Register of Space Objects. Earlier, however, the amendment of the Act on POLSA will be processed. The changes proposed in the draft act are aimed at: to streamline and clarify the scope of tasks of the Polish Space Agency, as an executive agency to provide the necessary expert support and technological knowledge to other public administration bodies involved in space activities, and responsible for the preparation and coordination of the implementation of the National Space Programme; and to adapt the supervision of POLSA to the solutions in force in other European countries, especially in the Member States of the European Space Agency (ESA), as well as to introduce improvements in the organisation of POLSA.

Polish Space Strategy was published by the Polish Ministry of Economic Development in February 2017. The objectives are: increasing competitiveness of the Polish space sector and its share in turnover (increasing participation in the EU space programmes: SST Support Framework), development of satellite applications, strengthening capacities in the area of security and defense using space (establishment of Space Situational Awareness System), creating favorable conditions for the development of space sector in Poland, building human resources for the Polish space sector. The strategic issue is to obtain 3\% of the EU market in 2030. National Space Plan (2019-2021) from 2018 states about the establishment, development and operation of a National Space Situational Awareness System (SSA) in cooperation with the EU SST consortium. The objective of the project is to enhance the security of citizens and infrastructure (Earth and space) in the context of space threats, to build national Space Situational Awareness (SSA) capabilities and to prepare for commercial exploitation of services provided in the area of SSA. The first stage of the activity is to launch basic functionalities of the national SST system (Space Surveillance and Tracking), inter alia, through the development of infrastructure and capabilities enabling the implementation of tasks envisaged within the framework of Poland's future membership in the European SST consortium. 19th of December 2018- Poland joined the European SST Consortium related to the tracking of space debris threatening infrastructure in space and on Earth. ${ }^{4}$

Poland has become a full member of the European Space Surveillance and Tracking Consortium. The accession agreement was signed on 19 December 2018 at the seat of the Polish Space Agency in Warsaw. Joining the consortium will enable national entities to participate in projects financed by the EU, whose budget in the current and future financial perspective may amount to more than EUR 350 million. Membership in the consortium will allow for faster development of the Polish SST system, which will provide our country with data necessary to protect the planned missions of Polish satellites and will support national security and defense in monitoring threats from artificial space objects. Participation in the European programme also brings great scientific and business potential. Ensuring the

\footnotetext{
${ }^{4}$ Polkowska (2019).
} 
operability of the observation sensors forming the Polish SST infrastructure, the possibility of their modernization and the demand for new ones-all this will facilitate a faster growth of competence in the area of SST and optical and radar observations for Polish entities, which already today gain experience by implementing projects under the optional SSA programme in ESA.

In view of the progressing commercialization of products related to situational awareness in space, domestic entities providing solutions and services in this area will be able to direct their offer also to the global market, which will grow as a result of the New Space trend, the increasing number of micro and smaller satellites, the planned development of mega-constellations and new areas such as satellite in-orbit servicing or, in the longer term, the sourcing of raw materials from celestial bodies. ${ }^{5}$ The Polish National Space Programme comes from December 2018 and still is in public consultations. Polish Space Agency (POLSA) ${ }^{6}$ will be responsible for the implementation of the programme. POLSA has considered a few areas of public support within the programme, such as, "Development of satellite systems"-with one of the priority projects: "Space Situational Awareness System". The vital goal of the project is to provide a long-term access to the European and national space infrastructure and the services crucial for securing its operations. As a consequence, a network of sensors (telescopes, lasers, radars) responsible for space object observation and tracking is to function on the territory of Poland and staff is to be trained in order to perform tasks in the frame of SST.

\section{Polish and the European Approach in SSA: Rising Stakes for Civilian Space Programmes}

The European Space Situational Awareness System (SSA) consists of three separate segments: Space Surveillance and Tracking, especially in the context of Space Debris (Space Weather) and Near Earth Orbit (NEO) observation. The European SSA system has dual-use civilian and military applications. Additional components to the SSA system may be added in the near future. They are built on the basis of military requirements and compiled by the European Defence Agency (EDA). The conference also devoted a lot of space to the development of the STM (Space Traffic Management $)^{8}$ system, which does not yet exist in Europe, unlike the USA. The goals for Space Situational Awareness are the following: society heavily dependent on critical space and ground assets, critical assets need to be protected against

\footnotetext{
${ }^{5}$ www.polsa.gov.pl.

${ }^{6}$ The Polish National Space Programme (www.polsa.gov.pl).

${ }^{7}$ Polkowska (2019).

8 "Space Traffic Management (STM) is the set of technical and regulatory provisions for promoting safe access into outer space, operations in outer space and return from outer space to Earth free from physical or radio-frequency interference."
} 
adverse effects from space, SSA Programme Declaration calls for independent European access to SSA data and services. There are three main areas: Space Weather, Near Earth Objects, Space Debris clean space. The participants in ESA SSA programs are 19 participating states. The good progress in the development of a SSA system in Europe has been observed and many actors involved: Member States, ESA, and EU. Distribution of roles needs to be finalized: development vs exploitation. There is still a performance gap in surveillance radars that is why there is a need to agree on a suitable governance scheme for the exploitation of future high performance European surveillance radar. There is a development of a high performance radar can be achieved within 3 years SWE and NEO systems will reach pre-operational status by $2020 .^{9}$

Thus, Europe has started its own preparatory programme of the SSA. International negotiations on permanent exchange of information and coordination, mainly with the USA, are also foreseen. Poland should also participate in these studies, which this year is to eventually become a member of the European SSA Consortium, where they play the biggest role: France, Germany, Great Britain (not in Consortium after Brexit) and Italy. ${ }^{10}$ Much of the data to be dealt with by the established Consortium can be found in public satellite catalogues created by the USA and other countries, which are available on the Internet and can be freely used. That is why transatlantic cooperation is so crucial. Orbital paths are constantly changing or are disturbed by a number of factors, such as inconsistent degrees of attraction, solar activity or the effects of gravity of other orbital objects. International cooperation on SSA data sharing is weakened by issues such as liability and property concerns, data formatting standards and compliance with catalogued tools, and finally security (some satellites do not provide data to the public). These issues are still being discussed in various international fora, including UN COPUOS (United Nations Committee on the Peaceful Uses of Outer Space). The author follows these discussions on an ongoing basis and makes use of them in her scientific work. Space security has a multidimensional concept. It can be understood as Security in Outer Space, Outer Space for Security or Security for Space. The first means the protection of the space infrastructure against natural and man-made threats or risks, ensuring the safety and sustainability of space activities. The second means the use of space systems for security and defence purposes. Security for Space means the protection of human life and the Earth environment against natural threats and risks coming from space.

There are also several meanings of such definitions as: Space Situational Awareness (SSA) which can be understood as current and predictive knowledge and understanding of the outer space environment including space weather and location of natural and manmade objects in orbit around the Earth; SEPP (Space Environment

\footnotetext{
${ }^{9}$ N. Bobrinsky, Forging ahead: from SSA to space safety, presentation at the 12th ESPI Autumn Conference, Vienna, September 2th 2018.

${ }^{10}$ P. Faucher, SST Support Framework: Safeguarding European space infrastructure. Overview, governance model, security relevance and future perspectives, presentation at the EUSST webinar 16 November 2020.
} 
Protection and Preservation), which is preventive and curative mitigation of negative effects of human activity in outer space on the safety and sustainability of the outer space environment and Space Infrastructure Security (SIS) as assurance of the infrastructure ability to deliver a service that can justifiably be trusted despite a hazardous environment.

There are some challenges to space infrastructure security, such as unintentional hazards (space debris, accidental interferences), intentional threats (ASAT, malicious interferences, and cyber attacks), Space weather hazards (geomagnetic storms, solar storms).

There are rising challenges to space infrastructure security. Space is an increasingly congested and contested resource. Space is multiple and diverse, there are different mitigation and protection measures. There are many actors playing in the Space, so interdependence between them has been noticed. There are various trends in Space, such as increasing space activity, new concepts, connected space, strategic target, "space control" capabilities, etc. The most important is growing dependence on space for society and economy at large. ${ }^{11}$

Growing security threats to civilian space programmes (access to space, cybersecurity in space, safe operations in space). Space is a critical infrastructure: satellites (jamming, spoofing, blinding), ground stations (hacking). Threats (military, non-military, natural) are understood and accepted and now are more properly and precisely assessed. Readiness to face and respond to threats is growing in governments and private sector. It seems that there is a possibility to invest in handling threats are developing and to find political solutions in managing threats. ${ }^{12}$

\section{Space and Cyber Security}

The constant growth in Space industry due to the globalization was one of the factors, which changed the meaning of the definition of "space security". The new emerging trends in "NewSpace" era caused the big amounts of risks. Launches are getting cheaper, satellites are getting smaller and more capable, venture capitalist funded private sector companies are entering the space market, new applications and services are driving the commercial market for connectivity, civil space spending is increasing. These factors are connected to the cyber threats as well. If the sector is to realize the government's aspiration of taking $10 \%$ of the global market by 2030 , the foundations must be safe, secure and sustainable — and therefore address cybersecurity. From a cybersecurity perspective this will result in a larger attack surface both in the space and ground segments and demonstrate a growing need to assure the

\footnotetext{
${ }^{11}$ S. Moranta (2018), Security in Outer Space: Perspectives on Transatlantic Relations, presentation at the 12th ESPI Autumn Conference Vienna, September 27th 2018.

${ }^{12}$ K. Uwe Schrögl (2018), Security in Outer Space: Rising Stakes for Civilian Space Programmes, 8 presentation at the 12th ESPI Autumn Conference Vienna, September 27th 2018.
} 
security of the integrated network, the manufacturing supply chain and the information transmission, analysis and storage. ${ }^{13}$

Governments, critical infrastructure, and economies rely on space-dependent services - for example, the Global Positioning System (GPS) — that are vulnerable to hostile cyber operations. However, few spacefaring states and companies have paid any attention to the cybersecurity of satellites in outer space, creating a number of risks. ${ }^{14}$ The commercialization of space provided the cybersecurity concerns for many reasons, including market incentives to lower costs and innovate quickly, often at the expense of software and hardware security. For example, networks of linked small-satellites can provide internet access, communications, data storage and transmission, imaging, and remote sensing. This next generation of satellites harnesses innovations in computing, electronics, miniaturization, imaging, sensors, big data, and artificial intelligence. Satellite services for Earth observations from space are growing. They support many policy and commercial purposes and contribute to agricultural productivity, transportation efficiency, and environmental monitoring. Commercial space activities use cutting-edge technologies and produce valuable data and are, thus, targets for cyber espionage, including economic cyber espionage, and cybercrime. $^{15}$

This situation is challenging. Some international agencies are involved in the project related to cybersecurity in space, such as the Space Generation Advisory Council (SGAC) in support of the United Nations Programme on Space Applications. ${ }^{16}$ One of the projects of the group refers to cyber risks in space. The objective of the project is referring to safety and security of the state. Satellite provide information and services to support global communications, the economy, security and defense, safety and emergency management, the environment and health. Their strategic value inevitably raises the issue of cybersecurity. The information they provide thus becomes a lucrative and enticing prospect for hackers. No more, considering how satellites and their associated infrastructure are critical to sustaining an increasingly globalised, and interconnected world. The space sector is unique in the field of cybersecurity. It is an industry where civil, commercial and military

\footnotetext{
${ }^{13}$ Bailey et al. (2019), (Accessed 3-12-2020), p. 7.

${ }^{14} \mathrm{https}$ ://www.cfr.org/report/cybersecurity-and-new-era-space-activities Accessed on 4 October 2020.

${ }^{15}$ https://www.cfr.org/report/cybersecurity-and-new-era-space-activities Accessed on 4 October 2020.

${ }^{16} \mathrm{SGAC}$ is a global non-governmental, non-profit organisation and network which aims to represent university students and young space professionals ages $18-35$ to the United Nations, space agencies, industry, and academia, representing many states, including Poland. SGAC was conceived at UNISPACE III in 1999, whereby states resolved, as part of the Vienna Declaration, "To create a council to support the United Nations Committee on the Peaceful Uses of Outer Space, through raising awareness and exchange of fresh ideas by youth. SGAC holds Permanent Observer status at the United Nations Committee on the Peaceful Uses of Outer Space (UN COPUOS) and regularly takes part in the annual meeting, as well as its Legal and Scientific and Technical Subcommittees.
} 
applications seamlessly co-exist, creating a haphazard situation for cybersecurity experts and telecommunication engineers. ${ }^{17}$

\section{Concluding Remarks}

Poland has been much involved in Space. That is why the Space Agency was created. Due to the big interest in Space industry the cooperation in Space is growing. Security in Space began the very important factor for the national defense and sovereignty as well. It seems that the cybersecurity issues are closely related to the security in Space. The Polish entrepreneurs involved in Space business should be aware of this while undertaking space activities. Space has reached an easy access and became the target for intruders. That is why the regulators of cybersecurity and space security should be aware of this new threat. The scope of the regulations of cyber threats has been broadened since the New Space era begun (smaller satellites and cheaper access to space for the public). This factor should be definitely taken into account for those, responsible for making national policies and strategies or security regulations in Poland.

\section{References}

Bailey B Speelman RJ Doshi PA Cohen NC Wheeler WA (2019) Defending spacecraft in the cyber domain in https://aerospace.org/sites/default/files/2019-11/Bailey_DefendingSpacecraft_ 11052019.pdf. Accessed 4 Oct 2020

Moranta S (2018) Security in Outer Space: Perspectives on Transatlantic Relations. Presentation at the 12th ESPI Autumn Conference Vienna, September 27th 2018

Polkowska M (2016) Polish space agency pursues task of developing country's space expertise, Room. The Space Journal 2(8)

Polkowska M (2019) European challenges in SSA. Poland example. Presentation at the Space Situational Awareness Workshop: Perspectives on the Future, Directions for Korea, Seoul 24-25 January 2019

Polkowska M, Ryzenko J (2016) Aktywność Polski w przestrzeni kosmicznej - nauka, polityka i prawo. Stan obecny, Gdańskie Studia Prawnicze XXXVI

Małgorzata Polkowska dr hab., associate professor at the War Studies University in Warsaw, specialist in Aviation and Space law, Security and Defense. In the years 2003-2017 an expert in the Civil Aviation Authority, since 2002 a lecturer at the University of War Studies and visiting professor of the University of Gdańsk and Rzeszów University of Technology. In 2013-2016, she was the first permanent Council Representative of the International Civil Aviation Organisation for Poland and the Central European Rotation Group (CERG); Lecturer at Polish and foreign

\footnotetext{
${ }^{17} \mathrm{https}: / /$ spacegeneration.org/projects/space-cybersecurity, Accessed on 4 October 2020.
} 
universities (including McGill University in Montreal, Canada, de Paul in Chicago, US, ENAC in Toulouse, France and University City of London, UK); speaker and moderator of a number of Aviation and Space conferences. Author of over 120 publications in Polish and English on International law, including air and space.

Open Access This chapter is licensed under the terms of the Creative Commons Attribution 4.0 International License (http://creativecommons.org/licenses/by/4.0/), which permits use, sharing, adaptation, distribution and reproduction in any medium or format, as long as you give appropriate credit to the original author(s) and the source, provide a link to the Creative Commons license and indicate if changes were made.

The images or other third party material in this chapter are included in the chapter's Creative Commons license, unless indicated otherwise in a credit line to the material. If material is not included in the chapter's Creative Commons license and your intended use is not permitted by statutory regulation or exceeds the permitted use, you will need to obtain permission directly from the copyright holder.

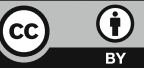

